\title{
THE EFFECT OF HALOTHANE WITH NITROUS OXIDE ON BAROREFLEX CONTROL OF HEART RATE IN MAN
}

\author{
Peter C. Duke and S. Trosky
}

ABSTRACT

\begin{abstract}
To assess the effect of halothane with 70 per cent nitrous oxide on the human baroreflex, we observed the heart rate response to pharmacological elevation of blood pressure in subjects anaesthetized to the $1 \mathrm{MAC}$ and $1.25 \mathrm{MAC}$ levels. We observed, in comparison to the awake control, that at I MAC halothane with 70 per cent nitrous oxide and oxygen, the baroreflex was depressed and this became more significant at $1.25 \mathrm{MAC}$ anaesthesia. In comparison to previous similar studies on the effect of halothane-oxygen anaesthesia, there was significantly less baroreflex depression at equianaesthetic doses with halothane with 70 per cent nitrous oxide.
\end{abstract}

EARLIER STUDIES in our laboratory demonstrated that halothane anaesthesia had a marked depressant effect on baroreflex control of heart rate in man.' In a poorly controlled study, Bristow, et al. suggested that there was no difference between the effect of anaesthesia with halothane and halothane-nitrous oxide on the human baroreflex ${ }^{2}$. Because halothane is used most often in combination with nitrous oxide, it was the purpose of this study to determine the effects of anaesthesia with halothane with nitrous oxide on the human baroreflex under well controlled conditions.

\section{Methods and Materials}

Baroreflex control of heart rate was assessed quantitatively by a pressor test described by Smyth, Sleight, and Pickering. ${ }^{3}$ We have previously described our method in detail, ${ }^{1,4,5}$ and a brief summary is included here. Systolic blood pressure is raised pharmacologically, resulting in reflex slowing of heart rate. Beat to beat systolic blood pressure and $R-R$ interval (measured in milliseconds), obtained from simultaneous recordings of direct arterial blood pressure and electrocardiogram (Lead 2), are linearly related over the period of blood pressure increase. The slope of this relationship is a measure of baroreflex sensitivity and is expressed in milli-

P. C. Duke, M.D., F.R.C.P.(C), Associate Professor; S. Trotsky, R.N., Department of Anaesthesia, Health Sciences Centre, University of Manitoba, Winnipeg, Canada.

This work was supported by a grant from the Canadian Heart Foundation.

Address reprint request to: Dr. P.C. Duke, Department of Anaesthesia, Health Sciences Centre, 700 William Avenue, Winnipeg. Manitoba, Canada R3E 0Z3. 53 seconds of $\mathrm{R}-\mathrm{R}$ interval change per $\mathrm{kPa}$ (torr) increase in systolic blood pressure. Slope values with correlation coefficients above 0.70 with probability values less than 0.05 are accepted in the results.

Five healthy unpremedicated male patients ranging in age from 19-30 years were studied prior to minor surgical procedures. All studies were carried out in accordance with institutional policies on human experimentation. The subjects were brought to the operating room two hours before the scheduled operations. A radial artery cannula was inserted percutaneously under local anaesthesia. The catheter was connected to a Trantec Model 800 transducer. The transduced signal was amplified and recorded on a calibrated Siemens Mingograph-800 recorder. Baseline recordings were obtained. Angiotensin amide in a dose range of $2.5-10 \mu \mathrm{g}$. was injected rapidly to produce an increase in systolic pressure of 2.66 to $3.99 \mathrm{kPa}$ (20 to 30 torr). Pressor tests were done with the subjects awake (awake control). Anaesthesia was then induced by mask, using only the agents under investigation. The trachea was intubated without the use of muscle relaxants. Ventilation was controlled to maintain an arterial $\mathrm{PCO}_{2}$ between $4.66-5.99 \mathrm{kPa}$ ( $35-45$ torr) verified by continuous end-tidal gas sampling. Inspired and end-tidal halothane concentrations were monitored continuously using a calibrated Beckman LB-II infrared analyzer purged with 70 per cent nitrous oxide. Anaesthetic equilibrations were considered complete when end-tidal halothane concentrations were within 10 per cent below inspired concentrations.

.Pressor tests were then done at two separate end-tidal halothane concentrations: at $0.26 \mathrm{per}$ cent end-tidal halothane with 70 per cent nitrous 


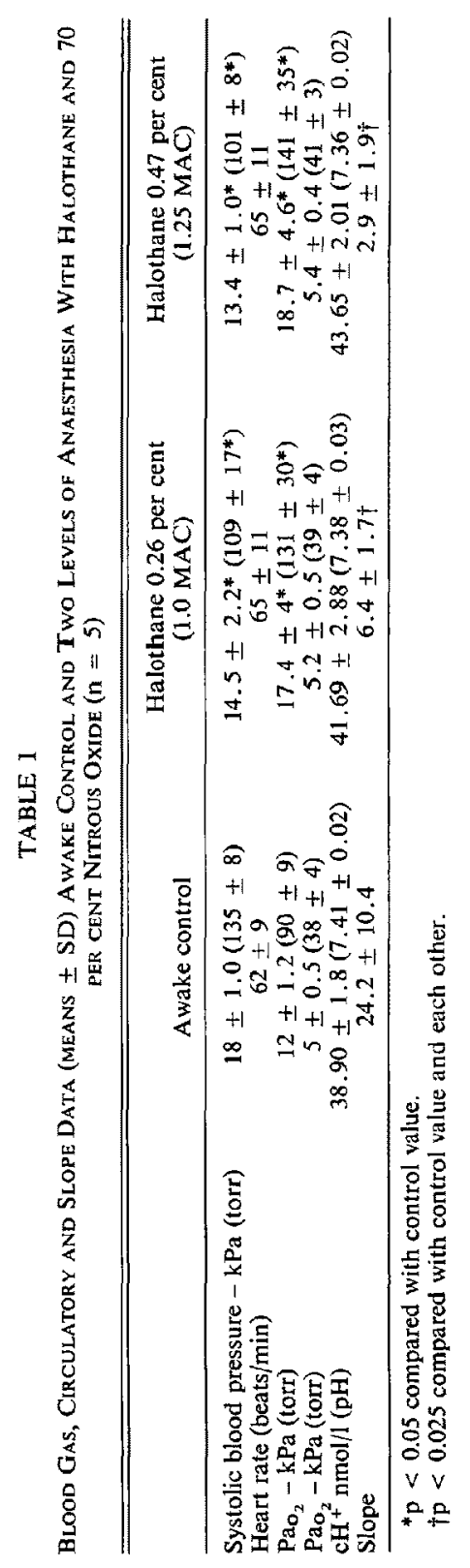


oxide ( 1 MAC equivalent) and at 0.47 per cent end-tidal halothane with 70 per cent nitrous oxide (1.25 MAC equivalent).

For each pressor test a linear regression equation and correlation coefficient were calculated by the method of least squares.

Statistical analyses of the results of the control and the two anaesthesia studies were done using the Student's t-test for paired data. Significance was accepted when probability values were less than 0.05 .

\section{RESULTS}

Table I compares the two levels of anaesthesia with the awake control situation. There were no differences in heart rate, $\mathrm{Pa}_{\mathrm{CO}_{2}}$ and $\mathrm{cH}^{+}(\mathrm{pH})$. With anaesthesia, resting systolic blood pressure decreased significantly from the control situation. As expected, $\mathrm{Pa}_{\mathrm{O}_{2}}$ increased during the anaesthesia studies because of an increased $\mathrm{F}_{\mathbf{I}_{2}}$. At $1 \mathrm{MAC}$ anaesthesia the mean slope for the five subjects was significantly decreased from the control. With a further increase in depth of anaesthesia to $1.25 \mathrm{MAC}$ there was a further decrease in the mean slope value. All three mean slopes were significantly different from one another $(p<0.025)$. Figure 1 illustrates the mean slopes obtained during the control situation and at the two anaesthetic depths in this study.

\section{Discussion}

Our results show that during anaesthesia at 1 MAC equivalent of halothane with 70 percent nitrous oxide, baroreflex function expressed in terms of heart rate response is decreased. This depression is dose related since deepening anaesthesia to the $1.25 \mathrm{MAC}$ level produced further reduction in baroreflex function. In a similar study ${ }^{1}$ we have reported that at less than 1 MAC halothane anaesthesia $(0.7$ percent endtidal), the baroreflex slope was significantly depressed (mean slope $\pm \mathrm{SD}=2.5 \pm 1.5$ ) and at 1.1 percent end-tidal halothane (approximately 1.25 $\mathrm{MAC}$ ), reflex response was abolished (mean slope $\pm \mathrm{SD}=0.03 \pm 0.04$ ). When comparing the slope for anaesthesia with $1 \mathrm{MAC}$ halothane and 70 per cent nitrous oxide to the former, there is significantly less depression of the reflex ( $p<$ 0.005 ). At the 1.25 MAC levels there is also less depression of reflex function in those subjects receiving halothane with nitrous oxide $(\mathrm{p}<0.05)$. This indicates that the addition of nitrous oxide

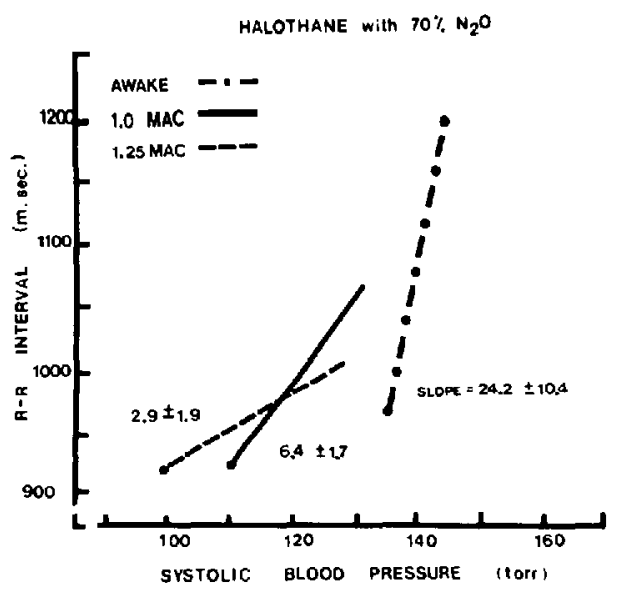

Figure I Mean awake slope is compared to those at 1.0 MAC and 1.25 MAC halothane with 70 per cent nitrous oxide. Each slope is significantly different from the others. Note that with increasing depth of anaesthesia, mean systolic blood pressure decreases, resulting in a resetting of the baroreflex.

has a beneficial effect in terms of maintaining some degree of reflex activity.

The effect of nitrous oxide alone on the baroreflex has not been adequately studied in man. Our attempts to do this failed, as four of our subjects became confused and unco-operative during the inhalation of the gas. Using techniques similar to ours, Bristow, et al. studied the effect of 70 per cent nitrous oxide in four subjects after premedication with meperidine and induction of anaesthesia with large doses of thiopentone. ${ }^{2}$ They found that baroreflex function was only partially depressed; that is, to a lesser degree than that seen with halothane or halothane with 70 per cent nitrous oxide. It was difficult to interpret their data because of the many drugs given and lack of control of anaesthetic depth in their studies.

Animal studies indicate that 70 per cent nitrous oxide alone produced only slight depression of the baroreflex in adult rabbits and a marked depression of the reflex in newborn rabbits (Gregory, G.A., unpublished). In cats, 80 per cent nitrous oxide had no effect on impulse traffic in the aortic depressor nerve. ${ }^{6}$

Similar human studies comparing equipotent levels of enflurane to enflurane-nitrous oxide anaesthesia demonstrated that there was no difference in the degree of baroreflex depression produced at the $1 \mathrm{MAC}$ level of anaesthesia. ${ }^{5}$ 
This may reflect the greater degree of cardiovascular depression seen with enflurane.

The heart rate remained constant during anaesthesia, while blood pressure decreased by an average of $3.46 \mathrm{kPa}$ ( 26 torr) at 1 MAC anaesthesia and $4.52 \mathrm{kPa}$ (34 torr) at 1.25 MAC anaesthesia. This alteration in blood pressure would usually produce a reflex increase in heart rate. This did not occur in our studies and indicates that resetting of the baroreflex occurs with halothane-nitrous oxide anaesthesia.

The baroreflex has been shown to be affected by age ${ }^{4}$ and increased arterial $\mathrm{PCO}_{2}$ above 45 torr $(5.99 \mathrm{kPa}){ }^{7}$ These variables were controlled in this study.

We did not control the type of ventilation or $\mathrm{Pa}_{\mathrm{O}_{2}}$ because we have previously reported these do not affect the baroreflex.'

With anaesthesia, resting blood pressure dropped as expected. This results in resetting of the reflex to function at a lower pressure. Does resetting itself result in a depressed reflex response? Arguments against this phenomenon have been outlined in previous reports. ${ }^{1,5}$

It is well known clinically that the addition of nitrous oxide to halothane to provide equianaesthetic levels improves cardiovascular function in $\operatorname{man}^{8}$ We feel that this cardiovascular stability can be attributed in part to the observed fact that there is less depression of baroreceptor reflex function with nitrous oxide supplementation.

\section{REFERENCES}

1. Duke, P.C., Founes, D. \& WAdE, J.G. Halothane depresses baroreflex control of heart rate in man. Anesthesiology 46: 184 (1977).

2. Bristow, J. D. \& Prys-Roberts, C., et al. Effects of anesthesia on baroreflex control of heart rate in man. Anesthesiology 3/: 422 (1969).

3. Smyth, H.S., Sleight, P. \& Pickering G.W. Reflex regulation of arterial pressure during sleep in man: a quantitative method of assessing baroreflex sensitivity. Circ. Res. 24: 109(1969).

4. DUKE, P.C., WADE, J.G., HiCKEY, R.F., etal. The effects of age on baroreceptor reflex function in man. Canad. Anaesth. Soc. J. 23: 111 (1976).

5. Morton, M., Duke, P.C. \& ONg, B. Baroreflex control of heart rate in man awake and during enflurane and enflurane-nitrous oxide anesthesia. Anesthesiology 52: 221 (1980).

6. Robertson, J.D., SWAN, A.A.B. \& Whit TERIDGE, D. Effect of anesthetics on systemic baroreceptors. J. Physiol. 131: 463 (1956).

7. Bristow, J.D., Brown, E.B., Cunningham, D.J.C., $e^{\prime} t$ al. The effects of hypercapnia, hypoxia, and ventilation on the baroreflex regulation of the pulse interval. J. Physiol. 216: 281 (1971).

8. Sмith, N.T.. Eger, E.I., Stoelting, R.K., et al. The cardiovascular and sympathomimetic responses to the additives of nitrous oxide to halothane in man. Anesthesiology 32: $410(1970)$.

\section{RÉSUMÉ}

Pour évaluer l'action de l'halothane sur le système barorécepteur reflexe de l'humain, on a étudié le comportement de la fréquence cardiaque après l'élévation de la tension artérielle induite pharmacologiquement chez des sujets anesthésiés aux niveaux MAC 1 el MAC 1.25. Lorsqu'on a comparé avec les contrôles obtenus au préalable chez les sujets éveillés, on a observé une dépression du système barorécepteur réflexe à MAC 1 par l'halothane dans un mélange protoxyde d'azote ( 70 pour cent) oxygène dépression qui s'accentuait lorsque le MAC atteignait 1.25. Cette dépression du système réflexe a été moindre à des concentrations équivalentes d'halothane dans le mélange protoxyde à 70 pour cent que celle rapportẻe lors d'études similaires antérieures. 